\title{
HUSBANDS' ROLE TO SUPPORT FOR WIVES WITH PREGNANCY ANEMIA AT DI CENTRO DE SAUDE COMORO MUNICIPIO DILI, TIMOR LESTE
}

\author{
Angelina da Costa Fernandes, Felysianus Sanga, Sabina Gero \\ Masters Program in Public Health, Nusa Cendana University
}

\begin{abstract}
Background: Anemia in pregnancy affects the health and well-being of pregnant women. It increases the risk of poor outcomes in pregnant mothers and offspring. The prevalence of anemia in pregnant women in Timor-Leste was 28 percent. This study was conducted to explore the role of husbands in accompanying wives with pregnancy anemia at the Centro de Saude Comoro Municipio in Dili, Timor Leste.

Subjects and Method: This was a descriptive qualitative with ethnography approach. This study was carried out at the Centro de Saude Comoro Municipio in Dili, Timor Leste. A sample of 38 people, consisting of husbands and wives, were selected for this study. The main informants were pregnant women with hemoglobin level less than $11 \mathrm{~g} / \mathrm{dL}$. The data were collected by indepth interveiw, and focus group discussion and analyzed using descriptive analysis technique.

Results: The role of husband in accompanying wife with pregnancy anemia was limited due to the lack of husbands' knowledge about anemia, its causes, and ways of handling. According to husbands' knowledge, pregnant women were not allowed to work too much, were advised not to drink coffee or tea. Husbands were supposed to provide wives with healthy food, help wives to cook and wash clothes, and to take wives for a walk as to relieve stress.

Conclusion: There is a need to strengthen the role of husband in accompanying pregnant wives with anemia. Their knowledge about anemia, its causes, and ways to handling it, should be enhanced.
\end{abstract}

Keywords: role, support, husband, knowledge, anemia, pregnancy

Correspondence: Angelina da Costa Fernandes. Masters Program in Public Health, Nusa Cendana University. Email: angelinafernandeso2@yahoo.co.id.

Mobile: +6281353801455 . 